\title{
Diabetes mellitus as a risk factor for aortic stenosis: from new mechanisms to clinical implications
}

\author{
Joanna Natorska1,2 \\ 'Department of Experimental Cardiac Surgery, Anesthesiology, and Cardiology, Institute of Cardiology, Jagiellonian University Medical College, Kraków, Poland \\ 2Krakow Center for Medical Research and Technologies, John Paul II Hospital, Kraków, Poland
}

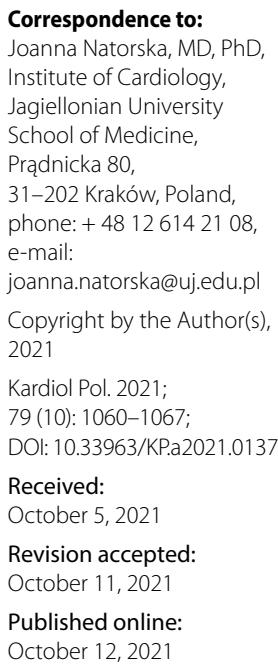

Correspondence to: Joanna Natorska, MD, PhD Institute of Cardiology, Jagiellonian University School of Medicine, Prądnicka 80, 31-202 Kraków, Poland, phone: + 48126142108 , e-mail:

joanna.natorska@uj.edu.pl Copyright by the Author(s), 2021

Kardiol Pol. 2021;

79 (10): 1060-1067;

DOI: 10.33963/KP.a2021.0137

Received:

October 5, 2021

Revision accepted:

October 11, 2021

Published online:

October 12, 2021

\begin{abstract}
Aortic stenosis (AS) is a progressive disease, with no pharmacological treatment. The prevalence of diabetes mellitus (DM) among AS patients is higher than in the general population. DM significantly increases the risk of AS development and the rate of its progression from mild to severe. However, the mechanism of the interaction between AS and DM is not fully understood. Limited data regarding the influence of hyperglycemia on valvular calcification are available while understanding the cross-talk between them is pivotal in designing an effective therapeutic approach to prevent or at least retard AS development and/or progression in DM patients. Analysis of aortic stenotic valves revealed that increased accumulation of advanced glycoxidation end products (AGEs) was associated with enhanced valvular oxidative stress, inflammation, expression of coagulation factors and markers of calcification. Moreover, AGEs valvular expression correlated with AS severity. Interestingly, in diabetic AS patients, valvular inflammation correlated only with long-term glycemic control parameters, i.e. glycated hemoglobin and fructosamine but not with serum glucose levels. It has been demonstrated that transcatheter aortic valve replacement (TAVI) is beneficial for AS patients also with concomitant DM and safer as compared to surgical aortic valve replacement (SAVR). Moreover, new antidiabetic drugs, such as glucagon-like peptide- 1 receptor agonists and sodium-glucose cotransporter- 2 inhibitors, targeting inhibition of AGEs-mediated oxidative stress, have been proposed to reduce the risk of AS development in DM patients. This review aimed to comprehensively discuss the impact of DM on AS and its potential therapeutic implications.
\end{abstract}

Key words: aortic stenosis, diabetes, hyperglycemia, inflammation, risk factors

Kardiol Pol 2021; 79, 10: 1060-1067

\section{INTRODUCTION}

Valvular heart diseases represent an important public health burden worldwide. With a decrease in the incidence of rheumatic disease, aortic valve stenosis (AS) has now become the most common valvular disease in Western countries. Its prevalence increases with age, affecting about $0.2 \%$ in 55 - to 64 -year-old individuals [ 1 ] and $2 \%-7 \%$ in subjects older than 65 years [2]. It is estimated that 4.5 million cases of AS will be present worldwide by the year 2030 [3]. In patients with the bicuspid aortic valve, which is the most common congenital heart disease occurring in 1\%-2\% of the population, AS development occurs statistically more frequently [2]. Growing evidence indicates that diabetes mellitus (DM) can increase the risk of AS development and the rate of AS progression [4-11]. The diagnosis of AS is based on echocardiographic assessment. The criteria for severe high-gradient AS include peak transvalvular velocity $\geq 4 \mathrm{~m} / \mathrm{s}$, the mean transvalvular pressure gradient $\geq 40 \mathrm{~mm} \mathrm{Hg}$, and aortic valve area $<1 \mathrm{~cm}^{2}$. In low-gradient or asymptomatic patients with AS when the valve morphology suggests AS, stress echocardiography is recommended [reviewed in 12].

The only definitive treatment for AS is surgical aortic valve replacement (SAVR) or transcatheter aortic valve replacement (TAVI). Both methods present great outcomes; however, surgical intervention remains the treatment of choice for the majority of AS patients [13]. Currently, there is a discussion whether TAVI is a better method of AS treatment than SAVR in patients with concomitant DM. The prevalence of DM is markedly higher among AS patients compared to the general population and was increasing during the last decade $[14,15]$.

AS is considered an atherosclerosis-like process. This concept is supported by a large number of studies showing 
that the development of AS is associated with cardiovascular risk factors such as smoking, obesity, hypercholesterolemia, arterial hypertension, chronic kidney disease, DM, and metabolic syndrome [5, 14]. Patients with DM are at 2- to 4-fold higher cardiovascular risk as compared to non-diabetic individuals, and cardiovascular disease (CVD) remains the leading cause of mortality in patients with this condition $[16,17]$. DM accompanied by inflammation is thought to be involved in the pathophysiological mechanism of atherosclerosis and is an important factor enhancing this disease [11]. Based on similarities between AS and atherosclerosis one might suspect the major importance of DM on AS progression; however, the mechanism underlying the cross-talk between DM and AS is not fully understood to date.

This review summarizes available data on the relationship between DM and AS, including the underlying mechanisms and clinical implications. Novel therapeutic approaches for AS patients with concomitant DM have also been discussed.

\section{PATHOMECHANISMS OF DEGENERATIVE AS}

AS initiated as aortic valve sclerosis is characterized by valve endothelial damage caused by high shear stress [18] and subendothelial accumulation of lipids and lipoproteins together with enhanced oxidative stress [19]. These processes result in the activation of local inflammation and drive cell-dependent mechanisms that regulate calcium load on the valve leaflets, leading to its calcification [20]. Under these pathological conditions, valvular interstitial cells (VICs), a predominant cell population within aortic valves, which are responsible for differences in the pathobiology of AS and atherosclerosis, play a substantial role in valvular calcification [21]. VICs differentiate into osteoblast-like cells, at least partially through epigenetic modifications [22]. Valvular calcification has been defined as a consequence of tightly regulated processes that culminate in the creation of an organized extracellular matrix deposition of osteoblast-like cells [22]. These activated cells are responsive to typical osteogenic mediators, such as transforming growth factor- $\beta$ superfamily members, and bone morphogenetic proteins (BMPs) $[23,24]$. BMPs stimulate the valve calcification by activating $S m a d 1 / 5 / 8$ and Wnt/ $\beta$-catenin signaling pathways, which leads to up-regulation of the master osteoblast transcription factor, Runx2/Cbfa1 (Runt-related transcription factor 2/core-binding factor $a-1$ ) [25]. Runx2/Cbfa 1 increases the expression of proteins directly associated with calcification and osteoblast differentiation: osteopontin, bone sialoprotein, and osteocalcin [23-25]. Several studies confirmed the up-regulation of these calcification markers in AS, both on mRNA and protein levels [23]. The late propagation phase of AS is driven by pro-osteogenic and pro-calcific factors, resulting in a complex and well controlled self-perpetuating calcification process [24, 26]. Moreover, it has been demonstrated that the regulation of valvular ossification and calcification is controlled by the nuclear factor $\mathrm{KB}$ (NF-KB) [27], suggesting its important role in the pathophysiology of AS. NF-KB is a master regulator of inflammatory responses that plays an essential role in the evolution as well as the resolution phase of inflammation. Overactivation of NF-KB is associated with many inflammatory diseases, i.e. with atherosclerosis [27]. NF-KB is activated by the tumor necrosis factor a, secreted by monocytes/macrophages and causes an upstream of interleukin 6, which has been implicated in calcification of aortic valve leaflets in AS patients via BMP-2 stimulation [27]. Moreover, the p65/c-Rel heterodimer of NF-KB has been shown to critically regulate the expression of tissue factor (TF) [28]. Indeed, it has been shown that stenotic aortic valves exhibit a procoagulant state [29-32]. The immunohistochemistry studies of twenty-one stenotic aortic valves have revealed the presence of large amounts of fibrin, which is the final product of blood coagulation. Interestingly, fibrin has been observed both on the surface and within stenotic valves [30]. The fibrin positive valve areas correlated with TF positive areas, suggesting that the conversion of fibrinogen to fibrin occurs in loco within the aortic valve [30]. In addition, it has been shown that the expression of coagulation proteins is associated with inflammation as the regions positive for TF and fibrin co-localized with regions of valve infiltration by macrophages $[31,32]$. The presence of both TF and fibrin and the number of macrophages correlated with the severity of AS (expressed as transvalvular maximum aortic gradient) and with the degree of valvular calcification [30]. These studies, as well as observations of other authors [32], suggest that coagulation might play a significant role in valvular fibrosis and calcification. Breyne et al. [32] have also shown that thrombin produced in loco leads to osteopontin activation and generation of the N-terminal domain with pro-inflammatory properties. Interestingly, both the quantity of fibrin and the degree of valve calcification correlated with factor (F)XIII expression derived mainly from the alternatively activated macrophages recruited to the valve leaflets [29]. Recently, it has been shown that VICs are also able to express prothrombin and active FX [11]. Moreover, growing evidence indicates that AS patients are characterized by impaired clot susceptibility to fibrinolysis [33, 34], the process closely regulated by specific inhibitors, such as plasminogen activator inhibitor type- 1 and thrombin-activatable fibrinolysis inhibitor [35]. In severe AS patients, the amounts of valvular fibrin positively correlated with prolonged fibrinolysis [34]. Although the direct relationship between vascular calcification and blood coagulation is still open for investigation, it seems that coagulation and fibrinolysis may be of major importance in the development/progression of AS.

\section{INFLUENCE OF DM ON ATHEROSCLEROSIS}

DM is a chronic disease characterized by hyperglycemia and frequently manifested by macrovascular myocardial infarction, stroke, peripheral arterial disease, and microvascular 
(retinopathy, nephropathy, and neuropathy) complications [36]. A global age-standardized prevalence of DM in the general population is $9.0 \%(7.2-11.1)$ in men and $7.9 \%$ (6.4-9.7) in women [37]. However, DM incidence is still increasing worldwide, and it is estimated that by the year 2045, there will be 700 million diabetic patients [38]. Type 2 DM constitutes $90-95 \%$ of diabetes cases worldwide and about one-third of type $2 \mathrm{DM}$ patients presents CVD, with the highest prevalence of coronary artery disease (21.2\%) and much lower that of stroke (7.6\%) [39]. CVD comprised about 50\% (95\% confidence interval [Cl] 37\%-64\%) of all deaths in type 2 DM patients $[39,40]$. Type 2 DM involves the combination of insulin resistance in peripheral tissues, due to obesity and genetic factors, with an inadequate pancreatic insulin response (or relative beta-cell failure). Hyperglycemia has multiple atherogenic effects that lead to the development of atherosclerosis in subjects with type $2 \mathrm{DM}$, based on longitudinal analysis [41]. Serum glycated albumin level and the ratio of glycated albumin to glycated hemoglobin $\left(\mathrm{HbA}_{1 \mathrm{c}}\right)$ were identified as potential surrogate parameters that are associated with or predict the progression of atherosclerosis in type 2 DM subjects [41, 42].

The pathophysiology of diabetic vascular disease is complex. An impact of DM on vascular complications is linked with hyperglycemia-induced leptin-to-adiponectin imbalance inflammation leading to local hypoxia, vascular dysfunction, and hemodynamic changes, favoring a prothrombotic state $[43,44]$. The impact of high blood glucose levels on vasculature is mediated by the high sensitivity of endothelial cells to persistent hyperglycemia, which leads to reactive oxygen species overproduction [45]. Additionally, hyperglycemia promotes the upregulation of genes responsible for the production of pro-inflammatory cytokines and matrix metalloproteinases that render atheromatous plaques more unstable, with a greater propensity for rupture [46]. Finally, platelet dysfunction and increased production of pro-thrombotic proteins, like fibrinogen and thrombin, contribute to a prothrombotic milieu in patients with DM [46].

\section{A PREVALENCE OF DM IN AS}

According to large clinical trials, the prevalence of DM was shown to be higher among AS patients than in the general population. In 2015 the CURRENT AS study comprising 3815 AS patients showed that $11.4 \%$ of individuals had concomitant DM [47]. Two years later, the PRIMID AS study revealed a $14.4 \%$ incidence of DM among AS patients [48]. Another study performed by Ljungberg et al. [15] showed in the Swedish population-based cohort study that the prevalence of DM was $15.8 \%$ ten years before aortic valve replacement due to AS. Notably, Culler et al. [14] showed that in the United States the prevalence of DM concomitant to AS increased from $19.7 \%$ to $31.6 \%$ between 2009 and 2015. Similar results have been reported in the Spanish population during a 15-year follow-up [49].

\section{CLINICAL TRIALS ON DM INFLUENCE ON AS DEVELOPMENT AND PROGRESSION}

Clinical interactions between DM and AS progression have been investigated by several authors (Table 1). However, available data are inconsistent, probably due to different methodological approaches implemented by researchers and further studies are needed. Aronow et al. [4] reported in 2001 in a retrospective study performed on 180 AS patients, including 48 with concomitant DM, that diabetic patients had higher annual progression in a peak systolic gradient than individuals without DM. In 2006 Katz et al. [5] have extended the previous observation by showing that both DM and metabolic syndrome increased the risk of valvular calcification. Kamalesh et al. [6], in a retrospective study

Table 1. Trials on diabetes mellitus (DM) and/or metabolic syndrome influence on aortic stenosis (AS) progression

\begin{tabular}{|c|c|c|c|}
\hline Study type & No. of patients & Conclusion & Ref. No. \\
\hline Retrospective & $\begin{array}{l}180 \text { mild AS patients, including } 48 \text { subjects } \\
\text { with concomitant DM }\end{array}$ & $\begin{array}{c}42.5 \% \text { higher annual progression in peak systolic gradient in DM } \\
\text { vs. non-DM patients }\end{array}$ & [4] \\
\hline $\begin{array}{l}\text { Prospective (the MESA } \\
\text { cohort) }\end{array}$ & $\begin{array}{c}6780 \text { participants, including } 1016 \mathrm{DM} \text { and/or } \\
\text { metabolic syndrome subjects }\end{array}$ & $\begin{array}{l}\text { Not only DM but also metabolic syndrome increases the risk of } \\
\text { aortic valve calcification both in women } \\
\text { ([RR] } 1.45 ; 95 \% \mathrm{Cl}, 1.11-1.90 \text { for metabolic syndrome and } \mathrm{RR} \\
=2.12 ; 95 \% \mathrm{Cl}, 1.54-2.92 \text { for } \mathrm{DM} \text { ) and in men (RR }=1.7 ; 95 \% \\
\mathrm{Cl}, 1.32-2.19 \text { for metabolic syndrome and } \mathrm{RR}=1.73 ; 95 \% \mathrm{Cl} \text {, } \\
\text { 1.33-2.25 for DM) }\end{array}$ & [5] \\
\hline Retrospective & 166 AS patients, including 72 with DM & $\begin{array}{l}\text { AS progression measured as AVA is faster in DM vs. non-DM pa- } \\
\text { tients (change during a median, } 2.5 \text { years follow-up was } 0.26 \mathrm{~cm}^{2} / \\
\text { /year in DM vs. } 0.20 \mathrm{~cm}^{2} / \text { year in non-DM patients; } P=0.02 \text { ) }\end{array}$ & [6] \\
\hline Prospective (CANHEART) & $\begin{array}{l}1.12 \mathrm{mln} \text { individuals observed for a median } \\
\text { of } 13 \text { years }\end{array}$ & $\begin{array}{c}20995 \text { subjects developed severe AS and a prevalence of DM was } \\
6 \% \text { higher compared to individuals who did not develop AS }\end{array}$ & [50] \\
\hline Observational & $\begin{array}{l}71483 \text { participants, including } 2377 \text { DM } \\
\text { patients }\end{array}$ & $\begin{array}{l}\text { Type } 2 \text { DM was associated with increased risk of } A S(H R=1.34 ; \\
\qquad 95 \% \mathrm{Cl}, 1.05-1.71)\end{array}$ & [8] \\
\hline Prospective & $\begin{array}{c}5079 \text { participants including } 1311 \mathrm{DM} \\
\text { patients }\end{array}$ & $\begin{array}{c}69 \text { participants developed AS during a mean follow-up of } \\
16.5 \text { years and DM was an independent risk factor for AS } \\
\text { development }(\mathrm{HR}=3.18 ; 95 \% \mathrm{Cl}, 1.51-6.69)\end{array}$ & [51] \\
\hline Prospective & $\begin{array}{c}203 \text { AS patients, including } 99 \text { participants } \\
\text { with metabolic syndrome and } 50 \text { with DM } \\
\text { observed for a mean of } 3.2 \text { years }\end{array}$ & Metabolic syndrome and DM had no impact on AS progression & [9] \\
\hline
\end{tabular}

Abbreviations: $\mathrm{AS}$, aortic stenosis; $\mathrm{AVA}$, aortic valve area; $\mathrm{Cl}$, confidential interval; $\mathrm{DM}$, diabetes mellitus; $\mathrm{HR}$, hazard ratio; $\mathrm{RR}$, relative risk 
Table 2. Advanced glycation end products (AGEs) influence on multiple biological processes.

\begin{tabular}{|c|c|c|}
\hline The type of response & Biological effects & Ref. No. \\
\hline $\begin{array}{l}\text { Oxidative stress } \\
\text { Reactive oxygen species production } \uparrow \\
\text { Superoxide dismutase function } \downarrow \\
\text { Nitric oxide } \downarrow\end{array}$ & $\begin{array}{l}\text { Lipid peroxidation } \uparrow \\
\text { Endothelial dysfunction } \uparrow \\
\text { Vasoconstriction } \uparrow\end{array}$ & {$[11,54,56,59,60]$} \\
\hline $\begin{array}{l}\text { Inflammation } \\
\text { VCAMs } \uparrow \\
\text { IL- } 1 \text {, TNF- } \beta \text {, IGF- } 1 \uparrow \\
\text { Mononuclear cell chemotaxis } \uparrow\end{array}$ & $\begin{array}{l}\text { Tissue remodeling and thickening } \\
\text { of the basement membrane } \uparrow\end{array}$ & {$[11,53,56,58,61-63]$} \\
\hline $\begin{array}{l}\text { Structural changes } \\
\text { Collagen changes leading to premature ageing } \\
\text { Irreversible cross-linking of structural fibers } \\
\text { Cell membrane and matrix changes } \uparrow\end{array}$ & Stimulation of pathological cellular activity $\uparrow$ & {$[51,58,64,65]$} \\
\hline $\begin{array}{l}\text { Coagulation and fibrinolysis } \\
\text { Tissue factor } \uparrow \\
\text { Platelet aggregation and fibrin stabilization } \uparrow \\
\text { Sensitivity of fibrin to plasmin } \downarrow\end{array}$ & $\begin{array}{l}\text { Thrombosis } \uparrow \\
\text { Fibrinolysis } \downarrow\end{array}$ & {$[11,56,66,67]$} \\
\hline
\end{tabular}

Abbreviations: IGF-1, insulin-like growth factor 1; IL-1, interleukin-1; TNF- $\beta$, tumor necrosis factor $\beta$; VCAMs, vascular cell adhesion molecules

performed on 166 consecutive AS patients, have shown faster disease progression in diabetics than in non-diabetic individuals; however, only in those with moderate AS. In a large cohort study comprising $1.12 \mathrm{mln}$ individuals followed for a median of 13 years, DM was associated with a 49\% higher risk for AS development [50]. Similar results were obtained by Larsson et al. [8], who have shown that type 2 DM was associated with a $34 \%$ increased risk of AS and Martinsson et al. [51], who have reported DM as an independent risk factor for AS development. On the other hand, Testuz et al. [9] have failed, during a 3-year follow-up, to observe the association between AS progression and metabolic syndrome or diabetes; however, in this study only fasting glucose levels were analyzed while it has been shown that long-term glycemic control may be of key importance $[10,11]$.

\section{MOLECULAR LINKS BETWEEN AS AND DM}

Despite the proven impact of DM on atherosclerosis and similarities between AS and atherosclerosis, limited data regarding the influence of hyperglycemia on valvular inflammation and calcification are available. However, hyperglycemia has been proposed among other metabolic factors to initiate or at least escalate valvular calcification through a complex mechanism involving vascular and inflammatory cell interactions [7, 52,53]. Immunohistochemistry analysis of AS valves revealed that concomitant DM was associated with an increased percentage of C-reactive protein-positive areas and correlated with the percentage of TF-positive areas [7]. Moreover, increased valvular protein glycation due to an accumulation of advanced glycoxidation end products (AGEs) has been suggested as a contributor to faster AS progression [54-57]. AGEs are a heterogonous group of proteins or lipids irreversibly glycated by the attachment of reducing sugars onto the free amino groups. AGEs modify tissue structure and function through cross-linking of intra-/extracellular matrix proteins or binding to the cell surface receptor for AGEs (RAGE), which affects multiple cellular processes (Table 2) [11, 51, 53, 54, 56, 58-67]. Ex- posure to increased blood levels of glucose in DM rapidly accelerates AGEs formation [68]. The rabbit and mouse models of AS proved that AGEs accumulation within aortic valves resulted in osteoblastic differentiation of VICs [68, 69]. Moreover, increased concentrations of AGEs lead to enhanced oxidative stress and NF-KB overexpression in the rabbit model of AS [69]. Moreover, RAGE-mediated NFKB activation has been implicated in the synthesis of inflammatory cytokines and TF by monocytes/macrophages [70]. Recently, AGEs-associated influence on AS progression has been shown in AS patients with concomitant DM, in whom a 6.6- and 12-fold increase in valvular and plasma AGEs was associated with AS severity, measured by the reduced aortic valve area [56]. Similarly, diabetic AS patients had 1.3-fold higher RAGE in plasma and 1.8-fold higher RAGE expression within aortic stenotic valves compared to non-diabetics [56]. Notably, solely plasma RAGE levels correlated with AS severity, while in patients with well-controlled type $2 \mathrm{DM}\left(\mathrm{HbA}_{1 \mathrm{c}}<7 \%\right)$, the influence of hyperglycemia on AS severity was negligible [56]. Diabetic AS patients compared to the non-diabetic ones had also enhanced NF-KB valvular expression in association with increased valvular expression of coagulation factors II and $\mathrm{Xa}$ and a marker of calcification, BMP-2 [11]. This observation has been confirmed by an in vitro study using VICs isolated from stenotic aortic valves, in which inhibition of either reactive oxygen species or NF-KB prevented calcification [11]. Interestingly, in diabetic AS patients valvular NF-KB expression correlated not only with long-term glycemic control parameters, namely $\mathrm{HbA}_{1 \mathrm{c}}$ and fructosamine but also with AS severity. Moreover, AS patients with poorly controlled type $2 \mathrm{DM}$ defined as $\mathrm{HbA}_{1 \mathrm{c}} \geq 6.5 \%$ were characterized by markedly higher plasma concentrations of TF and FVIla-antithrombin complex [11].

Available data suggest that poorly controlled DM in AS patients is associated with enhanced valvular oxidative stress, inflammation, and coagulation activation, as well as systemic prothrombotic state, which all together can trigger faster AS progression (Figure 1). 


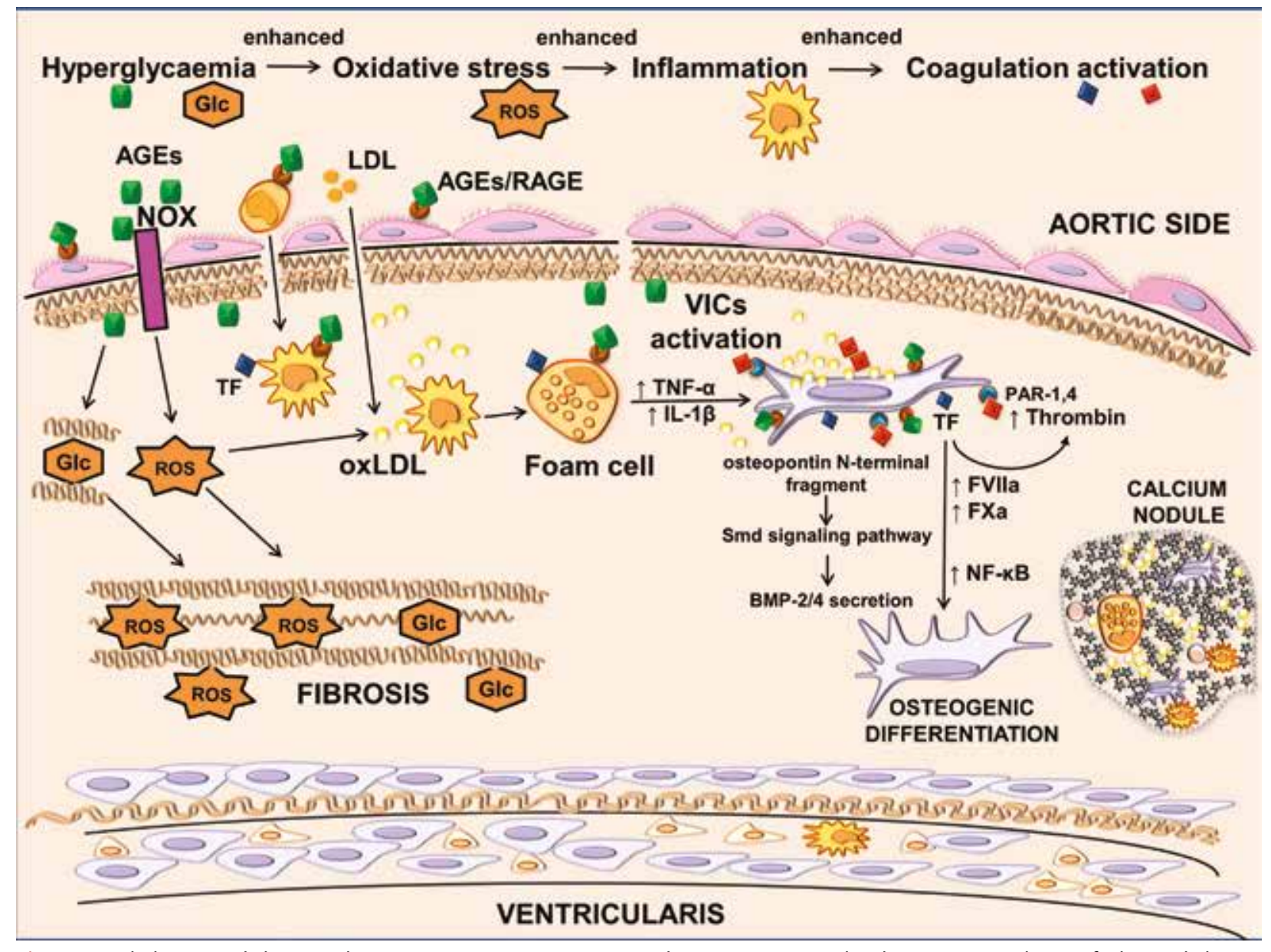

Figure 1. Links between diabetes and aortic stenosis progression. Hyperglycemia is associated with tissue accumulation of advanced glycation end products (AGEs), which are bound by a specific receptor (RAGE). AGEs accelerate aortic stenosis (AS) progression by several actions, including endothelial dysfunction and enhanced reactive oxygen species (ROS) generation via NADPH oxidase 2 (NOX2), the most important cellular producer of ROS. Amplified ROS generation leads to enhanced oxidation of low-density lipoproteins (LDL) and the formation of foam cells. AGEs/RAGE interaction enhances the synthesis of tumor necrosis factor a (TNF- $a$ ) and interleukin 1 $\beta$ (IL-1 $\beta$ ) by foam cells, which induces inflammation and activation of valvular interstitial cells (VICs), the most abundant cell population within aortic valves. VICs activation is associated with a transformation into cells with osteogenic phenotype via Smd-signalling pathway and secretion of bone morphogenetic proteins (BMPs) as potent osteogenic factors. Activated VICs, like macrophages, express tissue factor (TF), which together with activated factor VII (FVIIa) initiates a coagulation cascade. AGEs enhance coagulation activation and, consequently, increased expression of FXa and prothrombin are observed within aortic stenotic valves obtained from diabetic patients. Activated VICs express also nuclear factor KB (NF-KB), and its valvular expression is enhanced in AS patients with concomitant type 2 diabetes. Activation of the protease-activated receptors (PAR1, PAR-4) by thrombin additionally amplifies the inflammatory response of VICs. Accumulation of AGEs within aortic valves is also associated with glycation (GIc) of elastin and collagen fibers, scaffold fibers of aortic valves, with subsequent fibrosis of the valve leaflet

Thus, it can be assumed that maintaining long-term glycemic control parameters within normal values in AS patients with concomitant DM may slow the rate of AS progression.

\section{PRACTICAL IMPLICATIONS}

Although current data suggest an impact of DM on AS progression, there is a lack of treatment strategies for diabetic patients with AS to either improve the survival of AS patients or slow down the rate of AS progression. It is tempting to suggest that in diabetic AS patients, besides good glycemia control, long-term glucose dynamic control by measuring $\mathrm{HbA}_{1 \mathrm{c}}$ or fructosamine levels may be beneficial to prevent or at least slow down AS progression or its complications. However, large clinical trials are highly needed to verify whether maintaining $\mathrm{HbA}_{1 \mathrm{c}}$ or fructosamine within the normal range can retard AS progression in patients with mild-to-moderate AS and concomitant DM.

Based on animal and human studies, some therapies have been proposed, which may help to reduce cardiovascular complications in diabetic patients including those with AS. They include agents targeting inhibition of the AGEs-RAGE axis or its interaction with oxidative stress using pioglitazone or alagebrium (ALT-711), as well as new antihyperglycemic agents, such as glucagon-like peptide-1 receptor (GLP-1) agonists (liraglutide, luraglutide, and semaglutide) and sodium-glucose cotransporter-2 (SGLT-2) inhibitors (empagliflozin, canagliflozin, dapagliflozin, and ertugliflozin) [71]. However, to date there is no convincing evidence on their cardioprotective effect beyond blood-glucose control in 
diabetics. Another issue is that despite growing evidence that AGEs accumulation is associated with increased cardiovascular risk [71], their measurement has not been clinically validated.

Based on the COMPASS study, which was a multicenter, double-blind trial that included patients with a history of stable chronic atherosclerotic vascular disease, it has been shown that treatment with rivaroxaban $2.5 \mathrm{mg}$ twice daily combined with aspirin $100 \mathrm{mg}$ once daily was associated with a decreased risk of cardiovascular death, stroke, or myocardial infarction compared to patients treated with aspirin alone $[72,73]$. Taking into consideration that in vitro study performed on VIC cultures showed a substantial influence of rivaroxaban on suppression of inflammation, coagulation activation, matrix metalloproteinases, and finally cellular calcification [74], it might be hypothesized that NOACs are able to retard AS progression, at least in AS patients who require anticoagulation.

SAVR or TAVI are current treatment options for severe AS. TAVI is beneficial for AS patients with concomitant DM, who are subjected to this procedure instead of SAVR. However, data on the impact of DM on the prognosis of patients with severe AS who undergo TAVI vs. SAVR are limited and inconsistent. On one hand, a single-center large retrospective study showed that DM patients compared to non-DM individuals did not differ in the short-term outcome with regard to TAVI or SAVR [75]. On the other hand, Lindman et al. [76] in a post-hoc analysis of the PARTNER cohort showed that allcause one-year mortality was lower among DM patients after TAVI compared to those undergoing SAVR. A recent study performed on $254 \mathrm{DM}$ patients compared to 548 non-DM individuals undergoing TAVI showed that this procedure is not associated with an increased risk of short-term complications or mortality [77]. Similarly, Ando et al. [78] in a large cohort study performed on $70815 \mathrm{AS}$ patients showed that all-cause mortality in diabetic patients treated with TAVI was $2.8 \%$ compared to $3.6 \%$ in the SAVR group. Notably, a randomized trial performed on 586 AS patients treated with TAVI showed no difference in 30-day mortality between DM and non-DM patients [79]. Sun et al. [80] reported in a meta-analysis of 13253 AS patients that 1-year all-cause mortality after TAVI was similar in DM and non-DM individuals.

\section{CONCLUSIONS}

Available data suggest that DM is associated with increased prevalence of AS, leading to faster AS progression. However, it is not fully understood how DM influences AS progression, especially at early stages. It was also shown that glycemic control is not sufficient to prevent DM complications due to accumulation of AGEs, which are more important mediators of advanced glycation than hyperglycemia, resulting in enhanced oxidative stress and inflammation. Moreover, AGEs levels are better predictors not only for DM progression but also vascular calcification than $\mathrm{HbA}_{1 \mathrm{c}}$ [81]. In AS patients with concomitant type 2 DM valvular inflammation and calcification, markers were associated with $\mathrm{HbA}_{1 c}$ and fructosamine, underlying the need for strict long-term glycemic control. However, this observation should be confirmed in large prospective randomized trials.

\section{Article information}

Conflict of interest: None declared.

Acknowledgements: This work was supported by the grant from the Polish National Science Centre (UMO- 2018/29/B/NZ5/02629 to JN).

Open access: This article is available in open access under Creative Common Attribution-Non-Commercial-No Derivatives 4.0 International (CC BY-NC-ND 4.0) license, allowing to download articles and share them with others as long as they credit the authors and the publisher, but without permission to change them in any way or use them commercially. For commercial use, please contact the journal office at kardiologiapolska@ptkardio.pl.

How to cite: Natorska J. Diabetes mellitus as a risk factor for aortic stenosis: from new mechanisms to clinical implications. Kardiol Pol. 2021; 79(10): 1060-1067, doi: 10.33963/KP.a2021.0137.

\section{REFERENCES}

1. Coffey $S$, Cairns BJ, lung B. The modern epidemiology of heart valve disease. Heart. 2016; 102(1): 75-85, doi: 10.1136/heartjnl-2014-307020, indexed in Pubmed: 26541169.

2. Lindroos M, Kupari M, Heikkilä J, et al. Prevalence of aortic valve abnormalities in the elderly: An echocardiographic study of a random population sample. J Am Coll Cardiol. 1993; 21(5): 1220-1225, doi: 10.1016/07351097(93)90249-z, indexed in Pubmed: 8459080.

3. Deeb GM, Reardon MJ, Chetcuti S, et al. CoreValve US Clinical Investigators. 3-year outcomes in high-risk patients who underwent surgical or transcatheter aortic valve replacement. J Am Coll Cardiol. 2016; 67(22): 2565-2574, doi: 10.1016/j.jacc.2016.03.506, indexed in Pubmed: 27050187.

4. Aronow W, Ahn C, Kronzon I, et al. Association of coronary risk factors and use of statins with progression of mild valvular aortic stenosis in older persons. Am J Cardiol. 2001; 88(6): 693-695, doi: 10.1016/s00029149(01)01821-5, indexed in Pubmed: 11564402.

5. Katz R, Wong ND, Kronmal R, et al. Features of the metabolic syndrome and diabetes mellitus as predictors of aortic valve calcification in the Multi-Ethnic Study of Atherosclerosis. Circulation. 2006; 113(17): 2113-2119, doi: 10.1161/CIRCULATIONAHA.105.598086, indexed in Pubmed: 16636166.

6. Kamalesh M, Ng C, El Masry H, et al. Does diabetes accelerate progression of calcific aortic stenosis? Eur J Echocardiogr. 2009; 10(6): 723-725, doi: 10.1093/ejechocard/jep048, indexed in Pubmed: 19406839.

7. Natorska J, Wypasek E, Grudzień G, et al. Does diabetes accelerate the progression of aortic stenosis through enhanced inflammatory response within aortic valves? Inflammation. 2012; 35(3): 834-840, doi: 10.1007/s10753-011-9384-7, indexed in Pubmed: 21935671.

8. Larsson SC, Wallin A, Håkansson N, et al. Type 1 and type 2 diabetes mellitus and incidence of seven cardiovascular diseases. Int J Cardiol. 2018; 262: 66-70, doi: 10.1016/j.ijcard.2018.03.099, indexed in Pubmed: 29605469.

9. Testuz A, Nguyen V, Mathieu T, et al. Influence of metabolic syndrome and diabetes on progression of calcific aortic valve stenosis. Int J Cardiol. 2017; 244: 248-253, doi: 10.1016/j.ijcard.2017.06.104, indexed in Pubmed: 28684044.

10. Go JL, Prem K, Al-Hijji MA, et al. Experimental metabolic syndrome model associated with mechanical and structural degenerative changes of the aortic valve. Sci Rep. 2018;8(1): 17835, doi: 10.1038/s41598-018-36388-y, indexed in Pubmed: 30546028.

11. Kopytek M, Mazur P, Ząbczyk M, et al. Diabetes concomitant to aortic stenosis is associated with increased expression of NF-KB and more pronounced valve calcification. Diabetologia. 2021; 64(11): 2562-2574, doi: 10.1007/s00125-021-05545-w, indexed in Pubmed: 34494136.

12. Ágoston $G$, Morvai-Illés $B$, Pálinkás $A$, et al. The role of stress echocardiography in cardiovascular disorders. Kardiol Pol. 2019; 77(11): 1011-1019, doi: 10.33963/KP.15032, indexed in Pubmed: 31647477. 
13. Baumgartner $\mathrm{H}$, Hung J, Bermejo J, et al. Recommendations on the echocardiographic assessment of aortic valve stenosis: a focused update from the European Association of Cardiovascular Imaging and the American Society of Echocardiography. J Am Soc Echocardiogr. 2017;30(4):372-392, doi: 10.1016/j.echo.2017.02.009, indexed in Pubmed: 28385280.

14. Culler SD, Cohen DJ, Brown PP, et al. Trends in aortic valve replacement procedures between 2009 and 2015: has transcatheter aortic valve replacement made a difference? Ann Thorac Surg. 2018; 105(4): 1137-1143, doi: 10.1016/j.athoracsur.2017.10.057, indexed in Pubmed: 29394992.

15. Ljungberg J, Johansson B, Engström KG, et al. Traditional cardiovascular risk factors and their relation to future surgery for valvular heart disease or ascending aortic disease: a case-referent study. J Am Heart Assoc. 2017; 6(5): e005133, doi: 10.1161/JAHA.116.005133, indexed in Pubmed: 28476875.

16. Preis SR, Hwang SJ, Coady S, et al. Trends in all-cause and cardiovascular disease mortality among women and men with and without diabetes mellitus in the Framingham Heart Study, 1950 to 2005. Circulation. 2009; 119(13): 1728-1735, doi: 10.1161/CIRCULATIONAHA.108.829176, indexed in Pubmed: 19307472.

17. Holman RR, Sourij H, Califf RM. Cardiovascular outcome trials of glucose-lowering drugs or strategies in type 2 diabetes. The Lancet. 2014; 383(9933): 2008-2017, doi: 10.1016/s0140-6736(14)60794-7, indexed in Pubmed: 24910232.

18. Miller JD, Weiss RM, Heistad DD. Calcific aortic valve stenosis: methods, models, and mechanisms. Circ Res. 2011; 108(11): 1392-1412, doi: 10.1161/CIRCRESAHA.110.234138, indexed in Pubmed: 21617136.

19. Yeang C, Wilkinson MJ, Tsimikas S. Lipoprotein(a) and oxidized phospholipids in calcific aortic valve stenosis. Curr Opin Cardiol. 2016;31(4):440-450, doi: 10.1097/HCO.0000000000000300, indexed in Pubmed: 27205885.

20. Kizer JR, Benkeser D, Arnold AM, et al. Advanced glycation/glycoxidation endproduct carboxymethyl-lysine and incidence of coronary heart disease and stroke in older adults. Atherosclerosis. 2014; 235(1): 116-121, doi: 10.1016/j.atherosclerosis.2014.04.013, indexed in Pubmed: 24825341.

21. Akerström F, Barderas MG, Rodríguez-Padial L. Aortic stenosis: a general overview of clinical, pathophysiological and therapeutic aspects. Expert Rev Cardiovasc Ther. 2013; 11(2): 239-250, doi: 10.1586/erc.12.171, indexed in Pubmed: 23405844.

22. Yetkin $\mathrm{E}$, Waltenberger J. Molecular and cellular mechanisms of aortic stenosis. Int J Cardiol. 2009; 135(1):4-13, doi: 10.1016/j.jicard.2009.03.108, indexed in Pubmed: 19386374.

23. Nagy E, Eriksson P, Yousry M, et al. Valvular osteoclasts in calcification and aortic valve stenosis severity. Int J Cardiol. 2013; 168(3): 2264-2271, doi: 10.1016/j.ijcard.2013.01.207, indexed in Pubmed: 23452891.

24. Pawade TA, Newby DE, Dweck MR. Calcification in aortic stenosis: the skeleton key. J Am Coll Cardiol. 2015; 66(5): 561-577, doi: 10.1016/j. jacc.2015.05.066, indexed in Pubmed: 26227196.

25. Vadana M, Cecoltan S, Ciortan L, et al. Molecular mechanisms involved in high glucose-induced valve calcification in a 3D valve model with human valvular cells. J Cell Mol Med. 2020; 24(11): 6350-6361, doi: 10.1111/jcmm.15277, indexed in Pubmed: 32307869.

26. Demer LL, Tintut Y. Vascular calcification: pathobiology of a multifaceted disease. Circulation. 2008; 117(22): 2938-2948, doi: 10.1161/CIRCULATIONAHA.107.743161, indexed in Pubmed: 18519861.

27. Li YD, Ye BQ, Zheng SX, et al. NF-kappaB transcription factor p50 critically regulates tissue factor in deep vein thrombosis. J Biol Chem. 2009; 284(7): 4473-4483, doi: 10.1074/jbc.M806010200, indexed in Pubmed: 19095643.

28. Gao My, Chen L, Yang Lu, et al. Berberine inhibits LPS-induced TF procoagulant activity and expression through NF-kB/p65, Akt and MAPK pathway in THP-1 cells. Pharmacol Rep. 2014;66(3): 480-484, doi: 10.1016/j. pharep.2013.12.004, indexed in Pubmed: 24905527.

29. Kapusta P, WypasekE, Natorska J, et al. Factor XIII expression within aortic valves and its plasma activity in patients with aortic stenosis: association with severity of disease. Thromb Haemost. 2012; 108(6): 1172-1179, doi: 10.1160/TH12-07-0455, indexed in Pubmed: 23052999.

30. Natorska J, Marek G, Hlawaty M, et al. Fibrin presence within aortic valves in patients with aortic stenosis: association with in vivo thrombin generation and fibrin clot properties. Thromb Haemost. 2011; 105(2): 254-260, doi: 10.1160/TH10-09-0612, indexed in Pubmed: 21057695.

31. Natorska J, Marek G, Hlawaty M, et al. Evidence for tissue factor expression in aortic valves in patients with aortic stenosis. Pol Arch Med Wewn. 2009; 119(10): 636-643, indexed in Pubmed: 19847139.
32. Breyne J, Juthier F, Corseaux D, et al. Atherosclerotic-like process in aortic stenosis: activation of the tissue factor-thrombin pathway and potential role through osteopontin alteration. Atherosclerosis. 2010; 213(2): 369-376, doi: 10.1016/j.atherosclerosis.2010.07.047, indexed in Pubmed: 20732681

33. Natorska J, WypasekE, Grudzień G, et al. Impaired fibrinolysis is associated with the severity of aortic stenosis in humans. J Thromb Haemost. 2013; 11(4): 733-740, doi: 10.1111/jth.12122, indexed in Pubmed: 23289423.

34. Siudut J, Natorska J, Wypasek E, et al. Impaired fibrinolysis in patients with isolated aortic stenosis is associated with enhanced oxidative stress. J Clin Med. 2020; 9(6): 2002, doi: 10.3390/jcm9062002, indexed in Pubmed: 32630544.

35. Meltzer ME, Lisman $\mathrm{T}$, de Groot PG, et al. Venous thrombosis risk associated with plasma hypofibrinolysis is explained by elevated plasma levels of TAFI and PAI-1. Blood. 2010; 116(1): 113-121, doi: 10.1182/blood-2010-02-267740, indexed in Pubmed: 20385790.

36. Gregg E, Sattar N, Ali M. The changing face of diabetes complications. Lancet Diabetes Endocrinol.2016;4(6):537-547, doi: 10.1016/s22138587(16)30010-9, indexed in Pubmed: 27156051.

37. Saeedi $P$, Petersohn I, Salpea $P$, et al. Global and regional diabetes prevalence estimates for 2019 and projections for 2030 and 2045: results from the International Diabetes Federation Diabetes Atlas, 9th edition. Diabetes Res Clin Pract. 2019; 157: 107843, doi: 10.1016/j.diabres.2019.107843, indexed in Pubmed: 31518657.

38. Nair GG, Tzanakakis ES, Hebrok M. Emerging routes to the generation of functional $\beta$-cells for diabetes mellitus cell therapy. Nat Rev Endocrinol. 2020; 16(9): 506-518, doi: 10.1038/s41574-020-0375-3, indexed in Pubmed: 32587391

39. NCD Risk Factor Collaboration (NCD-RisC).. Worldwide trends in diabetes since 1980: a pooled analysis of 751 population-based studies with 4.4 million participants. Lancet. 2016; 387(10027): 1513-1530, doi: 10.1016/S0140-6736(16)00618-8, indexed in Pubmed: 27061677.

40. Siedlecki Ł, Szyguła-Jurkiewicz B, Szczurek W, et al. Mortality risk factors in patients with advanced heart failure and diabetes mellitus. Kardiol Pol. 2019; 77(6): 604-609, doi: 10.33963/KP.14813, indexed in Pubmed: 31066719.

41. Song SOk, Kim KJ, Lee BW, et al. Serum glycated albumin predicts the progression of carotid arterial atherosclerosis. Atherosclerosis. 2012; 225(2): 450-455, doi: 10.1016/j.atherosclerosis.2012.09.005, indexed in Pubmed: 23040867.

42. Haberka M, Machnik G, Kowalówka A, et al. Epicardial, paracardial, and perivascular fat quantity, gene expressions, and serum cytokines in patients with coronary artery disease and diabetes. Pol Arch Intern Med. 2019; 129(11): 738-746, doi: 10.20452/pamw.14961, indexed in Pubmed: 31479091

43. Paneni F, Beckman JA, Creager MA, et al. Diabetes and vascular disease: pathophysiology, clinical consequences, and medical therapy: part I. Eur Heart J.2013;34(31):2436-2443, doi: 10.1093/eurheartj/eht149, indexed in Pubmed: 23641007.

44. Rostoff $P$, Siniarski $A$, Haberka $M$, et al. Relationship among the leptin-to-adiponectin ratio, systemic inflammation, and anisocytosis in well-controlled type 2 diabetic patients with atherosclerotic cardiovascular disease. Kardiol Pol. 2020; 78(5): 420-428, doi: 10.33963/KP.15257, indexed in Pubmed: 32210218.

45. Naudi A, Jove M, Ayala V, et al. Cellular dysfunction in diabetes as maladaptive response to mitochondrial oxidative stress. Exp Diabetes Res. 2012; 2012: 696215, doi: 10.1155/2012/696215, indexed in Pubmed: 22253615.

46. Grant PJ. Diabetes mellitus as a prothrombotic condition. J Intern Med. 2007; 262(2): 157-172, doi: 10.1111/j.1365-2796.2007.01824.x, indexed in Pubmed: 17645584.

47. Taniguchi T, Morimoto T, Shiomi H, et al. CURRENT AS Registry Investigators. Initial surgical versus conservative strategies in patients with asymptomatic severe aortic stenosis. J Am Coll Cardiol. 2015; 66(25): 2827-2838, doi: 10.1016/j.jacc.2015.10.001, indexed in Pubmed: 26477634.

48. Singh A, Greenwood JP, Berry C, et al. Comparison of exercise testing and CMR measured myocardial perfusion reserve for predicting outcome in asymptomatic aortic stenosis: the PRognostic Importance of Mlcrovascular Dysfunction in Aortic Stenosis (PRIMID AS) Study. Eur Heart J. 2017; 38(16): 1222-1229, doi: 10.1093/eurheartj/ehx001, indexed in Pubmed: 28204448.

49. López-de-Andrés $\mathrm{A}$, Perez-Farinos N, de Miguel-Díez J, et al. Impact of type 2 diabetes mellitus in the utilization and in-hospital outcomes 
of surgical aortic valve replacement in Spain (2001-2015). Cardiovasc Diabetol. 2018; 17(1): 135, doi: 10.1186/s12933-018-0780-2, indexed in Pubmed: 30326902.

50. Yan AT, Koh M, Chan KK, et al. Association between cardiovascular risk factors and aortic stenosis: the CANHEART aortic stenosis study. J Am Coll Cardiol. 2017;69(12): 1523-1532, doi: 10.1016/j.jacc.2017.01.025, indexed in Pubmed: 28335833.

51. Martinsson A, Östling G, Persson M, et al. Carotid plaque, intima-media thickness, and incident aortic stenosis: a prospective cohort study. Arterioscler Thromb Vasc Biol. 2014; 34(10): 2343-2348, doi: 10.1161/ATVBAHA.114.304015, indexed in Pubmed: 25231637.

52. Lee MK, Han K, Kim MK, et al. Changes in metabolic syndrome and its components and the risk of type 2 diabetes: a nationwide cohort study. Sci Rep. 2020; 10(1): 2313, doi: 10.1038/s41598-020-59203-z, indexed in Pubmed: 32047219.

53. Verma N, Manna SK. Advanced glycation end products (AGE) potently induce autophagy through activation of RAF protein kinase and nuclear factor KB (NF-kb). J Biol Chem. 2016; 291(3): 1481-1491, doi: 10.1074/jbc M115.667576, indexed in Pubmed: 26586913.

54. Giacco F, Brownlee M. Oxidative stress and diabetic complications. Circ Res. 2010; 107(9): 1058-1070, doi: 10.1161/CIRCRESAHA.110.223545, indexed in Pubmed: 21030723.

55. Khan MS, TabrezS, Rabbani N, et al. Oxidative stress mediated cytotoxicity of glycated albumin: comparative analysis of glycation by glucose metabolites.J Fluoresc. 2015;25(6): 1721-1726, doi: 10.1007/s10895-015-1658-2, indexed in Pubmed: 26410776.

56. KopytekM,ZąbczykM, Mazur P, et al. Accumulation of advanced glycation end products (AGEs) is associated with the severity of aortic stenosis in patients with concomitant type 2 diabetes. Cardiovasc Diabetol. 2020; 19(1): 92, doi: 10.1186/s12933-020-01068-7, indexed in Pubmed: 32552684.

57. Saku K, Tahara N, Takaseya T, et al. Pathological role of receptor for advanced glycation end products in calcified aortic valve stenosis. J Am Heart Assoc. 2020; 9(13): e015261, doi: 10.1161/JAHA.119.015261, indexed in Pubmed: 32552251.

58. Forbes JM, Soldatos G, Thomas MC. Below the radar: advanced glycation end products that detour "around the side". Is HbA1c not an accurate enough predictor of long term progression and glycaemic control in diabetes? Clin Biochem Rev. 2005; 26(4): 123-134, indexed in Pubmed: 16648883.

59. Koulis C, Watson AMD, Gray SP, et al. Linking RAGE and Nox in diabetic micro- and macrovascular complications. Diabetes Metab. 2015 41(4): 272-281, doi: 10.1016/j.diabet.2015.01.006, indexed in Pubmed: 26323666

60. Devangelio E, Santilli F, Formoso G, et al. Soluble RAGE in type 2 diabetes: association with oxidative stress. Free Radic Biol Med. 2007;43(4): 511-518, doi:10.1016/j.freeradbiomed.2007.03.015, indexed in Pubmed: 17640561.

61. Verma N, Manna SK. Advanced glycation end products (AGE) potently induce autophagy through activation of RAF protein kinase and nuclear factor KB (NF-kb). J Biol Chem. 2016; 291(3): 1481-1491, doi: 10.1074/jbc. M115.667576, indexed in Pubmed: 26586913

62. Chen YJ, Chan DC, Chiang CK, et al. Advanced glycation end-products induced VEGF production and inflammatory responses in human synoviocytes via RAGE-NF-KB pathway activation. J Orthop Res. 2016; 34(5): 791-800, doi: 10.1002/jor.23083, indexed in Pubmed: 26497299.

63. Grauen Larsen H, Marinkovic G, Nilsson PM, et al. High plasma sRAGE (soluble Receptor for Advanced Glycation End products) is associated with slower carotid intima-media thickness progression and lower risk for first-time coronary events and mortality. Arterioscler Thromb Vasc Biol. 2019; 39(5): 925-933, doi: 10.1161/ATVBAHA.118.312319, indexed in Pubmed: 30917679.

64. Du R, Zhang RY, Lu L, et al. Increased glycated albumin and decreased esRAGE levels in serum are related to negative coronary artery remodeling in patients with type 2 diabetes: an Intravascular ultrasound study. Cardiovasc Diabetol. 2018; 17(1): 149, doi: 10.1186/s12933-018-0792-y, indexed in Pubmed: 30482197.

65. Mayer O, Gelžinský J, Seidlerová J, et al. The role of advanced glycation end products in vascular aging: which parameter is the most suitable as a biomarker? J Hum Hypertens. 2021;35(3):240-249, doi: 10.1038/s41371020-0327-3, indexed in Pubmed: 32203073.

66. Zhu W, LiW, Silverstein RL. Advanced glycation end products induce a prothrombotic phenotype in mice via interaction with platelet CD36. Blood.
2012; 119(25): 6136-6144, doi: 10.1182/blood-2011-10-387506, indexed in Pubmed: 22431576.

67. Yamagishi $S$, Adachi $H$, Takeuchi $M$, et al. Serum level of advanced glycation end-products (AGEs) is an independent determinant of plasminogen activator inhibitor-1 (PAl-1) in nondiabetic general population. Horm Metab Res. 2007; 39(11): 845-848, doi: 10.1055/s-2007-991176, indexed in Pubmed: 17992643.

68. Li F, Cai Z, Chen F, et al. Pioglitazone attenuates progression of aortic valve calcification via down-regulating receptor for advanced glycation end products. Basic Res Cardiol. 2012; 107(6): 306, doi: 10.1007/s00395012-0306-0, indexed in Pubmed: 23070070.

69. Hofmann B, Yakobus $Y$, Indrasari $M$, et al. RAGE influences the development of aortic valve stenosis in mice on a high fat diet. Exp Gerontol. 2014; 59: 13-20, doi: 10.1016/j.exger.2014.05.001, indexed in Pubmed: 24818652.

70. Lv B, Wang $H$, Tang $Y$, et al. High-mobility group box 1 protein induces tissue factor expression in vascular endothelial cells via activation of NF-kappaB and Egr-1. Thromb Haemost. 2009; 102(2): 352-359, doi: 10.1160/TH08-11-0759, indexed in Pubmed: 19652887.

71. Yang P, Feng J, Peng Q, et al. Advanced glycation end products: potential mechanism and therapeutic target in cardiovascular complications under diabetes. Oxid Med Cell Longev. 2019; 2019: 9570616, doi: 10.1155/2019/9570616, indexed in Pubmed: 31885827.

72. Bosch J, Eikelboom JW, Connolly SJ, et al. Rationale, design and baseline characteristics of participants in the cardiovascular outcomes for people using anticoagulation strategies (COMPASS) trial. Can J Cardiol. 2017; 33(8): 1027-1035, doi: 10.1016/j.cjca.2017.06.001, indexed in Pubmed: 28754388.

73. Kruger PC, Guzik TJ, Eikelboom JW. How can the results of the COMPASS trial benefit patients with coronary or peripheral artery disease in Poland? Kardiol Pol. 2019; 77(7-8): 661-669, doi: 10.33963/KP.14855, indexed in Pubmed: 31144674

74. WypasekE, Natorska J, Mazur P, et al. Effects of rivaroxaban and dabigatran on local expression of coagulation and inflammatory factors within human aortic stenotic valves. Vascul Pharmacol. 2020; 130: 106679, doi: 10.1016/j. vph.2020.106679, indexed in Pubmed: 32387621.

75. Mendez-Bailon M, Lorenzo-Villalba N, Muñoz-Rivas N, et al. Transcatheter aortic valve implantation and surgical aortic valve replacement among hospitalized patients with and without type 2 diabetes mellitus in Spain (2014-2015). Cardiovasc Diabetol. 2017; 16(1): 144, doi: 10.1186/s12933017-0631-6, indexed in Pubmed: 29121921.

76. Lindman BR, Pibarot $P$, Arnold SV, et al. Transcatheter versus surgical aortic valve replacement in patients with diabetes and severe aortic stenosis at high risk for surgery: an analysis of the PARTNER Trial (Placement of Aortic Transcatheter Valve). J Am Coll Cardiol. 2014; 63(11): 1090-1099, doi: 10.1016/j.jacc.2013.10.057, indexed in Pubmed: 24291272.

77. Abramowitz $\mathrm{Y}$, Jilaihawi $\mathrm{H}, \mathrm{Chakravarty} \mathrm{T}$, et al. Impact of diabetes mellitus on outcomes after transcatheter aortic valve implantation. Am J Cardiol. 2016; 117(10): 1636-1642, doi: 10.1016/j.amjcard.2016.02.040, indexed in Pubmed: 27015888.

78. Ando T, Akintoye E, Telila T, et al. Comparison of hospital outcome of transcatheter versus surgical aortic valve replacement in patients with diabetes mellitus (from the nationwide inpatient sample). Am J Cardiol. 2017; 119(8): 1250-1254, doi: 10.1016/j.amjcard.2016.12.026, indexed in Pubmed: 28219665

79. Chorin E, Finkelstein A, Banai S, et al. Impact of diabetes mellitus and hemoglobin A1C on outcome after transcatheter aortic valve implantation. Am J Cardiol. 2015; 116(12): 1898-1903, doi: 10.1016/j.amjcard.2015.09.032, indexed in Pubmed: 26602074.

80. Sun Y, Liu X, Chen Z, et al. Meta-analysis of predictors of early severe bleeding in patients who underwent transcatheter aortic valve implantation. Am J Cardiol. 2017; 120(4): 655-661, doi: 10.1016/j.amjcard.2017.05.035, indexed in Pubmed: 28668263.

81. Writing Team for the Diabetes Control and Complications Trial/Epidemiology of Diabetes Interventions and Complications Research Group. Sustained effect of intensive treatment of type 1 diabetes mellitus on development and progression of diabetic nephropathy: the Epidemiology of Diabetes Interventions and Complications (EDIC) study. JAMA. 2003; 290(16): 2159-2167, doi: 10.1001/jama.290.16.2159, indexed in Pubmed: 14570951 